\title{
The historical development of the pseudotumor concept
}

\author{
IAn Johnston M.D., Ph.D., F.R.C.S. \\ Department of Surgery, University of Sydney, Australia
}

\begin{abstract}
The author outlines the history of the development of the pseudotumor concept, first specifically formulated by Nonne in 1904 but implicit in earlier descriptions. A scheme of periodization is applied, identifying otological, neurosurgical, neurological, and neuroophthalmological periods; he relates theoretical and practical developments in the understanding of the condition to the concerns of the dominant speciality involved in diagnosis and management. Key studies from each period are discussed in relation to the issues of mechanism, origin, nomenclature, diagnosis, and treatment. During the otological period, approaches to the condition were heavily influenced by its common association with middle ear infection, often with venous sinus involvement, and this led to the idea of disturbed cerebrospinal fluid dynamics as the cause. The advent of neuroradiological systems ushered in the neurosurgical period in which the significant but unfinished debate began: which intracranial compartment is primarily implicated in the intracranial hypertension? By the time of the neurological period cerebral edema was implicated as the cause, and this coincided with the availability of appropriate treatment methods and steroidal and diuretic agents. Toward the end of this period additional major advances in investigative methods again brought the issue of mechanism into contention, although a resolution was not to follow. The neuroophthalmological period is characterized by an increased awareness of the significance of visual loss and a return to one of the original methods of treatment. Finally, the possible significance of impaired cranial venous outflow, a thread running through all periods, is considered.
\end{abstract}

\section{KEY WORDS • pseudotumor cerebri • hypertension • intracranial pressure • neurosurgical history}

The disease now most commonly referred to either as PTC or IIH has been known by various names since its first clinical descriptions, which are usually, but incorrectly, attributed to Quincke ${ }^{67,68}$ and Nonne $e^{65}$ over a century ago. This variation in nomenclature reflects the continuing uncertainty about the precise nature of the condition, an uncertainty also quite clearly reflected in the variations in ideas of origin and treatment. From a historical standpoint the initial recognition of the disease depended on two critical developments of much broader significance than their relevance to PTC alone. The first was the invention in 1851 of the ophthalmoscope by von Helmholtz and its application to neurology pioneered by von Graefe, Albutt, Hughlings Jackson and others, ${ }^{54}$ and the second was the introduction of lumbar puncture by Quincke around the turn of the century, which allowed objective measurement of the CSF pressure and analysis of its content. Likewise, the subsequent development of ideas regarding various aspects of the condition is closely linked to other important advances of wider application and it is of interest to examine the interrelationship between these advances and

Abbreviations used in this paper: CSF = cerebrospinal fluid; $\mathrm{CT}=$ computerized tomography; $\mathrm{ICP}=$ intracranial pressure; $\mathrm{IIH}=$ idiopathic intracranial hypertension; $\mathrm{PTC}=$ pseudotumor cerebri. approaches to the disease. Whereas the history is of undoubted intrinsic interest, a historical consideration of the disease itself provides, perhaps, the most comprehensive insight into the problems still associated with an understanding of the condition. Thus, although the intention of the present paper is to review the historical development of the pseudotumor concept over the 120 years since the first descriptions, implicit in this historical survey is an attempt to address some of the outstanding issues of nomenclature, mechanism, origin, and treatment by setting them within a historical context. A scheme of periodization will be applied which, although admittedly arbitrary, aims to reflect the importance of the interrelated factors of ideas of mechanism, methods of treatment and the speciality most involved in diagnosis and management, to the understanding of, and approach to, this still perplexing condition.

\section{INITIAL DESCRIPTIONS OF PTC}

The papers of Quincke ${ }^{67,68}$ and Nonne ${ }^{65}$ are generally taken to be the earliest works in which this syndrome was first recognized. The majority of their cases, however, were clearly not PTC as it is presently understood; furthermore, a number of cases were described prior to their 
reports that could be so identified, limitations of investigative methods notwithstanding. In reviewing these early descriptions (not all of which will be specifically referred to) two particularly interesting points emerge. The first is the association of the as yet unnamed syndrome with a number of the factors still recognized as having a close, and possibly etiological association with the condition, and the second is the use of several of the treatment methods currently advocated.

On the issue of the association with other conditions there were, between 1880 and 1900, several reports in which a recoverable raised ICP was linked with amenorrhea, ear disease, anemia, head injury, and intracranial venous occlusion. One of the earliest articles of relevance in English is a long section on diseases of the optic nerve in the Transactions of the Ophthalmological Society of the United Kingdom. ${ }^{40}$ Three descriptions within this stand out. The first is Hughlings Jackson's reference to reports by several ophthalmic surgeons of ".... a recoverable optic neuritis in young women suffering from uterine derangement." Apropos, there is the earlier observation by Foerster, quoted in several papers, in which he claims that all that is known about the connection between optic nerve disease and menstruation is that it exists. The second is Gowers' report ${ }^{29}$ of a 16-year-old young woman with relatively transient bilateral "optic neuritis" and an 11th cranial nerve palsy, and the third description by Broadbent of a young girl with a 2-year history of headache and vomiting with "double optic neuritis" associated with amenorrhea whose symptoms and signs resolved and in whom menstrual regularity was restored. Although she recovered, the effects of the papilledema caused permanent blindness. Elsewhere, also in 1881, Lawford ${ }^{53}$ described a 12-year-old-girl with a history of purpura who later developed bilateral papilledema with reduced visual acuity but without other signs and who later improved progressively over 9 months. Gowers ${ }^{29,30}$ reported two sisters, both of whom developed the characteristic clinical picture associated with anemia, and of whom he wrote that the clinical progress did "...not afford the slightest ground for suspicion of intracranial disease." He also referred to another case described in his book, Medical Ophthalmoscopy. In relation to ear disease, Taylor wrote in the 1890 edition of The Practice of Medicine: "It is important to remember what has now been verified in numerous cases that in mastoid suppuration there is often double optic neuritis with an entire absence of meningitis or of abscesses proved by postmortem examination, or by recovery after simple trephining of the mastoid cells." He described a typical case in his 1894 review of optic nerve disorders (Case 6). ${ }^{84}$ In an interesting article, in which he analyzed 57 patients who died of complications from otitis media, Newton Pitt, ${ }^{64}$ in 1890, described three other patients, all of whom had ear disease with papilledema but no other signs of central nervous system involvement, who recovered; in one of these patients the lateral sinus was explored, the clot removed, and the internal jugular vein ligated.

On the matter of treatment, Carter ${ }^{15,16}$ described the use of optic nerve decompression to alleviate the ophthalmological effects of raised ICP, referring to the initial description of the technique by De Wecker, ${ }^{22}$ with whose surgical approach he disagreed. In the first of two articles, Carter described the case of a 26-year-old maid who, 10 days after sustaining a minor head injury, developed headache and loss of vision with marked bilateral papilledema but no other findings. Despite treatment (iodide of sodium and mercurials) her eye signs worsened and she underwent a left optic nerve decompression. There was subsequent improvement in association with resolution of her papilloedema. Victor Horsley, who for a brief period had advocated De Wecker's operation, became a proponent of cranial decompression for ICP-induced optic neuritis in general and spoke of the benefits in the discussion following Taylor's aforementioned article. ${ }^{84}$

Finally, mention must be made of the article byWilliamson and Roberts ${ }^{91}$ that appeared in 1900. The authors analyzed 100 cases of double optic neuritis. The article is brief, but the patients in their Groups IX and X probably constitute the first well-described cases of PTC within the diagnostic limitations of the time. There are, in these groups, 21 patients-13 females (average age 16.8 years [range 10-22] and eight males (average age 17.1 years [range 10-40 years]). Of particular importance is that the follow-up period for 20 of the patients, averaged 4.4 years. On the issue of incidence, they wrote that "Most medical men who have paid much attention to cerebral diseases will have met with a case or cases of this kind." Other salient features in this article include the recognition of the importance of looking for an association with ear disease and hematological disorders and the exclusion of Bright disease and syphilis. In terms of treatment, they note the importance of Horsley's advocacy of cranial decompression and also the possibility of lumbar puncture.

\section{QUINCKE AND NONNE-THE DEFINITION OF A DISEASE}

The articles by Quincke ${ }^{67,68}$ and Nonne, ${ }^{65}$ spanning the years 1893 to 1904, initiated the concept of PTC or IIH as a specific disease entity, although the authors' objectives were different and most of the cases described would not even remotely be acceptable by current criteria, which is in striking contrast to the cases described in the previous section. Quincke, in his 1897 article, ${ }^{68}$ certainly attempted to define a clinical entity that he called "meningitis serosa." He attributed the clinical features to raised ICP and postulated as a cause an increase in CSF secretion mediated by the autonomic nervous system. His list of etiological factors (head injury, stress, excessive alcohol consumption, pregnancy, influenza, and otitis media) includes several still considered viable today. Of the 10 cases he described, however, (seven females, and three males) only the descriptions of two, both female, conform somewhat to the current concept of PTC. Both patients suffered headache, papilledema, and raised CSF pressure with normal composition, and deterioration of visual acuity was evident in one. On the other hand both were said to have presented with loss of consciousness. Nonne's objectives were different, ${ }^{65}$ his interest being in cases that had, on presentation, the clinical features of an intracranial tumor but whose subsequent course appeared to preclude this diagnosis. In all, he described 18 patients and, as with Quincke, only two might be currently accepted as having PTC. The first of these, a 25-year-old man, sustained a concussion during a fight. Shortly thereafter he developed severe headache and was described as having third, fourth, 
and sixthcranial nerve palsies, severe bilateral papillede$\mathrm{ma}$, and a CSF pressure of $600 \mathrm{~mm} \mathrm{H}_{2} \mathrm{O}$. After undergoing six lumbar punctures, with drainage of 15 to $20 \mathrm{ml}$ of fluid on each occasion, he recovered and subsequently remained well. The second patient, a 27-year-old woman, had a 2-year history of chronic suppurative otitis media followed by a 2-week history of headache, dizziness, vomiting, and diplopia. On examination bilateral papilledema and a left sixth cranial nerve palsy were demonstrated. Based on a diagnosis of cerebral abscess, operative exploration was undertaken, which revealed only a left thrombosed lateral sinus. She subsequently experienced a spontaneous recovery with only mild residual optic atrophy. Nonne concluded that she had hydrocephalus secondary to transverse sinus thrombosis that was caused by her ear disease, a diagnosis suggestive of Symond's otitic hydrocephalus (vide infra).

Thus, as a result of the work of these two authors, it may be said that the concept of a specific disease entity had been advanced with one name based on a proposed mechanism (that is, meningitis serosa due to an increase in CSF volume), an enduring postulate, but then attributed to increased production. Of particular importance was the introduction of lumbar puncture, still a mainstay of diagnosis, and recognition of the primary diagnostic dilemma presented by patients with this condition, differentiation from an intracranial mass, which also remains the same as today and was responsible for the other, and, more lasting, name PTC.

\section{THE OTOLOGICAL PERIOD-OTITIC HYDROCEPHALUS}

This period is taken as the years between two landmark studies, beginning with Passot's thesis ${ }^{66}$ in 1913 (never, to my knowledge, published elsewhere ${ }^{65}$ and culminating in Symonds' three papers in the 1930s in which the term "otitic hydrocephalus" was introduced, the essential clinical features outlined, and the mechanistic link with middle ear disease via cranial venous sinus involvement established. ${ }^{80-82}$ There were, of course, antecedents to Passot's descriptions as discussed in detail in his introduction, and also outlined briefly in the section on Initial Descriptions of Pseudotumor Cerebri. A number of aspects of Symonds' descriptions are as pertinent today as they were originally, although happily, chronic middle ear infection is much less prevalent. The most important aspect of Passot's study is his systematic analysis of aseptic meningitis of otitic origin of which he identifies two kinds: les etats hypertensifs and les meningitis varies. It is the first, which he also calls "hydropisie meningee" that corresponds to PTC. Apart from speculation on mechanism, still applicable today is Passot's description of an increase in ICP due to hyperproduction of CSF in the subarachnoid space and ventricles, with an absence of elements or albumin in the fluid, which occurs in association with "banale" ear disease in children and young adults and is immediately and definitively relieved by drainage of CSF. Two other points of interest include: 1) the description of a similar condition induced by a blow to the head rather than ear disease; and 2) his claim that, in fact, a clear clinical distinction is possible from hydrocephalus. In this study, too, the value of lumbar puncture, both diagnostic and therapeutic, is stressed.
Sir Charles Symonds published three papers in the 1930 s, the first in $1931^{82}$ in which, following a detailed review of the literature, he described three pediatric patients who developed raised ICP in association with middle ear disease; it was in this report that Symonds introduced the term "otitic hydrocephalus". He was impressed by the large volumes of CSF drained by lumbar puncture in these patients (as, indeed, Passot had been) and concluded that there was free communication throughout the CSF-containing spaces. His postulate was that after otitis media, and with a variable relation to venous sinus involvement, there might develop a condition of "... increased ICP due to the presence of an excess of normal CSF" and suggested the term otitic hydrocephalus as a title which "...implies no active process of inflammation and, being deprived of the qualification internal or external, will include fluid both within the ventricles and the subarachnoid space". ${ }^{82}$ As a mechanism he proposed "...either an excessive secretion from the choroid plexus or a defective absorption through the arachnoid villi" and recommended drainage of CSF by lumbar puncture as the rational form of treatment. ${ }^{82}$ In two subsequent papers, published in 1932 and $1937,,^{80,81}$ he elaborated on this concept and, of particular interest, described several other cases with a similar syndrome associated with infection of nonotitic origin but also attributable to cranial venous sinus involvement. One such case, separately described by Ellis, was an infant with an infection of the umbilical vein and multiple venous thromboses, who developed ventriculography-evidenced hydrocephalus related to superior sagittal sinus thrombosis, which was demonstrated by direct sinography. None of Symonds' own cases, incidentally, had ventriculography-hence, his persistence with the term hydrocephalus.

Apart from the work of these two men there were, during this period, a number of reports in which the condition was predominantly discussed in relation to middle ear disease. In 1914 Warrington wrote a long and detailed study that he titled, "Intracranial serous effusions of inflammatory origin". ${ }^{88}$ Several of the cases he described, particularly the pediatric ones, would seem to fit the description of PTC. In 1924 Adson, ${ }^{2}$ in a paper entitled "Pseudobrain abscess", described three patients who presented with raised ICP and other central nervous system signs following ear infection but who were found not have an abscess. ${ }^{2}$ This clinical picture he attributed to localized encephalitis without abscess formation. Lillie and Lillie, ${ }^{56}$ in the following year, described four cases of "choked disc" with mastoid disease but without abscess formation or visible venous sinus thrombosis. These seemed typical cases of postotitic PTC, as were the two cases by Mygind in $1922 .{ }^{63}$ The first was a young woman with acute suppurative otitis media in whom CSF pres-sure was initially 400 $\mathrm{mm} \mathrm{H}_{2} \mathrm{O}$ with 26 lymphocytes in the fluid. One week later she developed papilledema and a sixth cranial nerve palsy accompanied, after a short interval, by headache and vomiting. At that time her CSF pressure was $950 \mathrm{~mm} \mathrm{H}_{2} \mathrm{O}$, although the fluid was, by then, of normal composition. Over the following 6 months her symptoms and signs almost completely resolved but her CSF pressure remained significantly elevated $(600 \mathrm{~mm} \mathrm{H} \mathrm{O})$. The second case was similar but without the initial abnormality of CSF composition. In 1919, Aboulker, ${ }^{1}$ like Passot before him, recognized two syndromes of aseptic meningitis ac- 
companying ear disease: 1) diffuse with excess of cells and protein; and 2) hypertensive with fluid of normal composition, which obviously corresponds to PTC. ${ }^{1}$ Two other papers published during this period, also relating to ear disease, are deserving of mention. In 1928, Leidler $^{55}$ was probably the first to describe the appearance of PTC after internal jugular vein ligation, one component of treatment of inflammatory ear disease; and in 1930, Cairns ${ }^{13}$ reported a case of a pure intracranial hypertension syndrome after mastoiditis, which raised the possibility of excess formation, or deficient absorption of CSF, as a causative mechanism. The latter report, together with that by Frazier ${ }^{26}$ in the same year in which he described 22 cases of what he called "cerebral pseudotumor" are, perhaps, suitable forerunners to the description of the neurosurgical period. Interestingly, most of Frazier's patients underwent decompressive surgery, and 19 were alive and well from 1 to 25 years after diagnosis.

\section{THE NEUROSURGICAL PERIOD- NEURORADIOLOGY AND SUBTEMPORAL DECOMPRESSION}

The coining of the term otitic hydrocephalus in the 1930 s coincided with the dramatic developments in neuroradiology that resulted in the availability of ventriculography, pneumoencephalography, and angiography. Almost immediately, then, the concept of hydrocephalus in relation to this condition was invalidated, and the enduring problem of how to relate the apparent increase in CSF volume, suggested particularly by the large volumes demonstrated on lumbar CSF drainage and the distension of the subarachnoid space observed during ventriculography and cranial decompression, was first formulated. Apart from issues of mechanism, which will be considered further in the following paragraphs, the investigation of patients with this condition now became the particular province of the neurosurgeon, who was charged with the exclusion of a tumor or other intracranial mass lesion; this role also gave particular relevance to Nonne's term PTC and variants thereof. In addition, the neurosurgeon was often responsible for treatment, which now became divided between lumbar punctures for the milder cases and cranial, particularly subtemporal, decompressive procedures for those that proved refractory.

The two key neurosurgical papers from this period, the first to include the delineation of the ventricular system, were written by Davidoff and Dyke ${ }^{21}$ and by Walter Dan$\mathrm{dy}^{18}$ in 1937. The cases were similar in the two reports, but the conclusions as to mechanism were quite different. Davidoff and Dyke described 15 patients (11 females and four males) who ranged in age from 4 to 43 years, who presented with a more or less pure intracranial hypertension syndrome. Six patients had had either otitis media or some other infection whereas, interestingly, nine had suffered no antecedent abnormalities. In all cases ventriculographic studies were essentially normal, and all, apart from one patient who did not require any treatment, responded well to cranial (13 subtemporal and one posterior fossa) decompressive procedures. The authors noted, however, that despite the rapid symptomatic improvement, the "... final disappearance of papilledema required from 6 months to several years". They had one patient who died 3 months after treatment of unrelated causes in whom postmortem examination of the brain demonstrated unremarkable findings. On the issue of mechanism these authors concluded that there was a disequilibrium between CSF production and absorption. Fremont-Smith wrote what, in the light of present views, might be considered a somewhat prescient comment, appended to the article: "My hunch is that the majority of cases will turn out to be due to the failure of absorption rather than an excessive production of fluid." 21

Dandy ${ }^{18}$ described 22 patients in whom ventriculography demonstrated normal findings and who predominantly underwent subtemporal decompressive surgery. Whereas Davidoff and Dyke ${ }^{21}$ had used the term "hypertensive meningeal hydrops," Dandy preferred the noncommittal (in terms of mechanism) but rather cumbersome appellation "intracranial pressure without brain tumor". All of his patients recovered; a significant number of them were later reviewed and reported in the study by Zuidema and Cohen in $1954 .{ }^{93}$ In this report, 12 of Dandy's original 22 patients were traced. Ten were alive and well whereas two had died, one of an intracranial aneurysm 15 years after the initial diagnosis and one of multiple sclerosis. The origin of the controversy over which compartment, blood, brain, or CSF, is involved as the cause of intracranial hypertension in this condition may be attributed to Dandy. Prior to his paper all attention, including that of Davidoff and Dyke who were the first to report normal ventricular size, had focused on CSF circulation and volume. Dandy, however, believed, as have many subsequent writers, that the absence of ventricular dila-tion precluded a disturbance of CSF circulation. He also thought that the chronicity of the condition precluded cerebral edema as a cause. He was impressed by the rapid fluctuations in tension evident in patients who had undergone subtemporal decompressive procedures and thought that transient changes in cerebral blood volume were responsible for the intracranial hypertension.

Several other important, although not specifically surgery-related, papers appearing in the 1930s merit mention. In 1937, McAlpine ${ }^{59}$ described cases of "external hydrocephalus", which he also called "toxic hydrocephalus": cases of a pure intracranial hypertension syndrome following infection other than that of the middle ear. He likened these to Quincke's descriptions of meningitis serosa and postulated an overproduction of CSF as the cause. In 1939, Gardner ${ }^{28}$ described 10 cases, all of which were associated with ear infection, and in the majority of which lateral sinus occlusion was present. He, like a number of writers before him, was impressed by the large volumes of CSF drained by lumbar puncture in this condition, but stressed that, in his view, such volumes did not necessarily indicate an overall excess of CSF nor did the often-observed distension of the subarachnoid space necessarily indicate excess CSF in that compartment; rather this might reflect local accumulation due to release at the site. This idea was later addressed by Foley ${ }^{25}$ in his 1955 paper. On the question of origin, Thomas, ${ }^{85}$ in 1933, described two female patients with generalized edema occurring only during the menstrual period, both of whom suffered severe headache and blurred vision; in one bilateral papilledema and raised CSF pressure were indicated 
by examination after lumbar puncture. This was the first clear suggestion of a possible endocrine basis for the condition, particularly in obese young women, who later came to be recognized as typically afflicted by the disease. A similar case, more completely investigated and labeled PTC, was described by McCullagh ${ }^{60}$ in 1941. The first recognition of another important etiological factor appeared in a 1933 report by Cameron ${ }^{14}$ who described marked bilateral papilledema with impaired visual acuity in chronic respiratory disease. Very few studies were published during the years of World War II and the decade thereafter. The resurgence of interest in the late 1950s ushered in what I have called the "neurological period."

\section{THE NEUROLOGICAL PERIOD-BENIGN INTRACRANIAL HYPERTENSION, CEREBRAL EDEMA, AND STEROIDS}

This is, perhaps, the least defined period but extends approximately from the late 1950 s to the 1980 s. It is identified to focus on the shift from the primacy of neurosurgery in diagnosis and management, which is seen as related to three particular developments somewhat spread over this period. The first was the growing conviction that cerebral edema was the cause of intracranial hypertension, a belief given for the first time some observational foundation by the 1956 study of Sahs and Joynt. ${ }^{74}$ The second was the availability of medical methods of treatment, essentially steroid and diuretic agents, which were seen as capable of acting against cerebral edema. With the two main drugs, Diamox and dexamethasone, of course, considerable influence on CSF dynamics exists, and with the latter there is a very problematical relationship to the condition with actions that are both causal and curative. ${ }^{72,90}$ The third major development during this period was that of CT scanning, which quickly and entirely obviated the need for neurosurgical involvement in investigation, although this was, to some extent, already happening with the progressive improvement in and increasing reliance on, cerebral angiography to exclude an intracranial mass lesion. The upshot of these developments was that neurologists were now able to diagnose and treat patients with PTC, needing recourse to the neurosurgeon only in cases relatively refractory to treatment.

It is of interest that the start of this period, which I dated from the two important papers by Foley ${ }^{25}$ in 1955 and by Sahs and Joynt ${ }^{74}$ in 1956 , was heralded in 1956 by a return to the subject by two key investigators, Symonds and Davidoff from the two preceding periods. Symonds, in a reflective paper, ${ }^{83}$ reconsidered the applicability of the term otitic hydrocephalus which he had introduced in 1931; he had changed his views on mechanism, coming round to Gardner's postulate that venous engorgement producing cerebral edema was the significant causal factor. He also described the case of the only patient at that time who died following lumbar puncture, 3 weeks after the onset of acute right otitis media in which both lateral sinuses were obstructed. On the question of treatment he recognized that many patients did well if left untreated but believed that if treatment was required serial lumbar punctures should be the first-line, followed by a subtemporal decompressive procedure if the CSF pressure was not set- tling. He clearly did not conclude from the patient who died after lumbar puncture that the risk of coning precluded this form of treatment, although he did raise the matter when discussing his preference for ventriculography over encephalography. Davidoff's paper, ${ }^{20}$ in which he abandoned his earlier nomenclature in using the title "Pseudotumor Cerebri", was basically a detailed clinical report of 61 cases followed over a long period (1-22 years). There were no new insights into mechanism, but his work in the paper did contribute to defining the clinical features and establishing the good outcome.

Returning to the two aforementioned papers, that of Foley $^{25}$ is historically most notable for the introduction of the term "benign intracranial hypertension," which became the most commonly used term for the next several decades. He defined the syndrome thus: “....prolonged intracranial hypertension without ventricular abnormality, focal neurological signs, or disturbance of awareness or intellect, the most important symptoms being headache of moderate degree, obscurations of vision, diplopia, and sometimes tinnitus; marked papilloedema and abducens palsies are the only signs. The CSF is normal in composition and the prognosis is almost invariably good, the condition subsiding within a few weeks or months".

Although this may seem now a somewhat sanguine view, it was an important paper at the time, not only because it introduced a new and widely accepted term but also because it contributed significantly to the definition of the condition and reported some rudimentary studies of cerebral blood flow in which the $\mathrm{N}_{2} \mathrm{O}$ technique was used in an effort to address the issues of mechanism first raised by Dandy. ${ }^{18}$ The issue of mechanism was the specific focus of the second paper, that of Sahs and Joynt, ${ }^{74}$ in which they described 17 patients, in all of whom the diagnosis of PTC/IIH would definitely be reached based on current criteria. The follow-up period ranged from 1 to 16 years (average 8.7 years), and there were no unexpected late developments. They attributed the increased ICP to cerebral edema on theoretical grounds, as Sahs had done in an earlier article written with Hyndman in $1939^{73}$ and, in putting their hypothesis to the test, demonstrated intracellular and extracellular edema on brain biopsy samples obtained in 10 of the 17 cases. This paper certainly signaled a reversal in the concept of mechanism, although it may be, and indeed has been, criticized on methodological grounds and for failing to address satisfactorily the considerable theoretical problems associated with the edema hypothesis.

\section{Aspects of the Condition}

From the considerable number of papers published during this period, far too numerous to cover in detail, three aspects of the condition may be identified, from the historical viewpoint, as having received particular attention: origin, mechanism, and outcome.

Origin. On origin, although a large number of individual factors were identified for the first time (many of which might bear more critical examination), four are paramount, not only for their etiological role but for their implications regarding mechanism. The role of steroidal agents was first identified as causative by Laurence, et al., ${ }^{52}$ in 1960 , and by 1964 , Walker and Adamkiewicz ${ }^{86}$ 
were able to amass 24 cases reported up to that time. Vitamin A, known since 1954 from the experimental work of Millen, et al., ${ }^{61}$ to influence CSF circulation, was clearly identified as causally important (as hypovitaminosis A) by Feldman and Schlezinger ${ }^{24}$ in 1970 who, in a detailed literature review, found six other cases in adults prior to 1970. Hypervitaminosis A had already been implicated by Morrice, et al., ${ }^{62}$ in 1960 . A clear, but still poorly understood, association with obese young women, menstrual irregularity, and pregnancy was also recognized in the 1960 s in the work of Wilson and Gardner ${ }^{92}$ and in a series of papers by Greer, ${ }^{31-34}$ although some information on this had already been published (see the section on Otological Period). Finally, a possible familial incidence was first described in obese sisters by Buchheit, et al., ${ }^{11}$ in 1969. These findings were, of course, subsequently extended to include different generations, twins, and a link with communicating hydrocephalus. ${ }^{45}$

Mechanism. The second aspect was mechanism. It seems probable that an understanding of mechanism might have been been refined by the extraordinary number of new techniques that became available in the later part of this period. These are listed briefly with references to their first, or most important, use in relation to the mechanism of PTC: radionuclide techniques, ${ }^{6} \mathrm{CSF}$ infusion methods, ${ }^{57} \mathrm{ICP}$ monitoring, ${ }^{47} \mathrm{CBF}$ studies,${ }^{58} \mathrm{CT}$ scanning, ${ }^{70}$ magnetic resonance imaging, ${ }^{77}$ and positron emission tomography scanning. ${ }^{9}$ In summary, although CT and magnetic resonance imaging raised our ability to exclude other causes of raised ICP in PTC/IIH to new levels of sophistication and noninvasiveness, none of these methods solved the riddle of mechanism. In several reviews published around this time, ${ }^{3,43,71}$ the areas of continuing controversy were clearly identified. Thus, the issue of mechanism remained unresolved although the trend was clearly toward a return to the initial ideas of disturbed CSF dynamics, albeit in a somewhat more refined formulation.

Outcome. The third and final aspect being considered, outcome, was particularly examined in a series of studies between 1968 and 1982.8,12,17,35,46,89 In addition to the fact that each study comprised over 100 cases and that each advanced the general understanding of the clinical aspects of the condition, the studies were novel in that they provided more complete outcome data than had been previously available. The two areas of special relevance were: 1) the likelihood of late revelation of diagnostic error, which was encouragingly low; and 2) the incidence of persistent visual problems, which was discouragingly high. It was the latter that played a significant part in ushering in the next period.

\section{THE NEUROOPHTHALMOLOGICAL PERIOD- VISUAL LOSS AND THE RETURN OF OPTIC NERVE SHEATH DECOMPRESSION}

This final period of the present schematization is also the shortest-dating from the mid-1980s to the present. It is distinguished by two particular features. The first was the developing awareness, alluded to earlier and related to an increased sophistication in methods of evaluation, that visual disturbances, both at the time of presentation and as long-term consequences, were much more significant than hitherto realized. It was this realization that called into question the epithet, "benign," encouraging a change in terminology, a more aggressive approach to treatment, and a substantially greater involvement of the neuroophthalmologist. Studies of particular importance in this development were those of Corbett, et al., ${ }^{17}$ in 1982, Gutgold-Glen, et al., ${ }^{36}$ in 1984, and Wall and George ${ }^{87}$ in 1991. Whereas ophthalmological attention had earlier focused primarily on the severity of papilledema and loss of visual acuity, it was now directed more at visual field defects being detected by the newer methods of evaluation. The second, and related, development started somewhat earlier when the old method of optic nerve sheath decompression to alleviate the adverse ophthalmological effects of papilledema was rediscovered. The first reawakening of interest in this technique was reported in $1969^{78}$ but it was particularly the 1988 series of papers published in the Archives of Ophthalmology that accelerated its usage in PTC/IIH. ${ }^{10,49,75}$ Although there is no question that the neuroophthalmological consequences of PTC/IIH have become much better understood as a result of the ophthalmological involvement in diagnosis, the applicability of optic nerve sheath decompression in this condition must still be considered unproven.

\section{CRANIAL VENOUS OUTFLOW IMPAIRMENT- THE NEXT PERIOD?}

One clear theme running through the development of ideas thus far outlined, but not closely conforming to the imposed method of periodization, is the role of impaired cranial venous outflow in the pathogenesis of PTC. There is some suggestion, however, based on recent conceptual and technical developments, that a focus on the role of venous disease might be the next phase in the study of PTC and, moreover, might hold the promise of being more fundamental, in both theoretical and practical terms, than its predecessors. Clearly, a relationship of venous involvement with PTC, particularly in conjunction with middle ear disease, was recognized in some of the very earliest reports on PTC. The position by the time of the transition from the Otological to the Neurosurgical periods is best summarized in the writings of Symonds ${ }^{80-82}$ and of Gardner, ${ }^{28}$ as previously discussed. Thus, venous, predominantly transverse, sinus occlusion was seen to be a common but by no means invariable accompaniment of PTC in middle ear disease, and some cases of PTC with sinus involvement, particularly superior sagittal, were seen apart from ear disease. By the time of Symonds' 1956 paper $^{83}$ both writers had concluded that venous engorgement with edema was the cause of the intracranial hypertension. Two other important developments were the introduction of direct sinography $1937^{27}$ and the recognition that extracranial (internal jugular) venous obstruction could cause PTC, both with ligation in the treatment of ear infection or in other conditions, as first documented by Evans. ${ }^{23}$

Attention to this aspect was, however, somewhat sporadic over the following decades, although there were two important papers, in the first of which ${ }^{69}$ the authors focused on diagnosis and treatment and in the second of which $^{42}$ the authors focused particularly on mechanism. 
Parallel to these intermittent reports there were studies aimed at acquiring a more general understanding between the relationship of venous obstruction and intracranial hypertension and CSF dynamics. Of importance, particularly with respect to the latter, are the early studies of Dandy and Blackfan ${ }^{19}$ and the later reports of Bering and Salibi $^{7}$ and of Guthrie, et al. ${ }^{37}$ Finally, in the last two decades, there have been a number of related developments that encourage the view expressed at the start of this section. In summary they are as follows. First, venous outflow impairment has been seen as underlying a number of different causes of PTC, both those in which it is relatively obvious such as disseminated lupus erythematosus, ${ }^{76}$ Behcet disease, ${ }^{41}$ chronic respiratory disease, ${ }^{14}$ and heart failure, ${ }^{4}$ as well as in those in which the relationship is still rather speculative such as obesity ${ }^{79}$ and head injury. ${ }^{5}$ Second, there is now quite a number of documented cases in which venous outflow obstruction is seen to cause either a pseudotumor syndrome (cases disqualified from the strict application of PTC by the presence of radiologically detected abnormalities) or hydrocephalus. ${ }^{44}$ Third, there have been two studies in which the authors have specifically suggested a universal etiological role for venous outflow impairment in PTC but one only revealed by sophisticated studies of venous outflow pressures. ${ }^{48,50}$ Fourth, there are several reports of direct treatment of venous disease in PTC both by surgical bypass ${ }^{39}$ and by neuroradiological methods. ${ }^{51}$

\section{CONCLUSIONS}

From this historical review of a putative disease entity described in various ways for over 100 years, several interesting points, both specific and general, emerge. First, despite the volume of literature-and well over 1000 germane papers have been written - considerable uncertainty remains regarding major aspects of the condition, particularly nomenclature, cause, mechanism, and treatment. Even in terms of the relatively resolved questions of clinical features and diagnosis, contention exists between those who would adhere to strict criteria, identifying a relatively "pure" condition (that is, IIH) and those who would take a more inclusive approach on the basis of a supposed common mechanism (that is, PTC). ${ }^{44}$ Were this issue to be resolved, however, the names in use would not in any way be indicative of disease mechanism. None of the former terms has endured and, indeed, could not be expected to, until the mechanism is understood. The uncertainties about cause, as already outlined, also bear on terminology. On this point the particular problems have been the large number of presumed etiological factors identified, often on a largely anecdotal basis, and the inability, in many cases, to identify the operative mechanism. It is notable that certain factors recognized in the very early descriptions remain the most securely in place even if, again, the precise mechanism is still obscure. Indeed, on mechanism in general, as has been shown, the pendulum has swung across the range of possibilities (at least in terms of which intracranial compartment is primarily to be inculpated) and back to its original position. Inextricably linked to this continuing uncertainty on mechanism is the variation in treatment methods, which is favored at any one time. Again, one of the very earliest methods, abandoned for many decades, is now enjoying a considerable resurgence. Clearly, none of the methods used to date has adequately addressed the basic problem, which remains unidentified, although the return of interest in venous outflow problems does carry the promise of addressing this, at least to some extent and at least in some cases. The fundamental assumption, then, in the study of the condition is that if the mechanism could be elucidated, nomenclature could be made appropriate, the role of etiological factors properly understood, and the treatment rationally directed. As the final statement in a historical survey it is salutary to consider this assumption against the background of the vigorous theoretical debate that engaged doctors in the immediate pre- and post-Christian centuries, between the Rationalists, Empiricists, and Methodists. ${ }^{38}$ Although it is probably true to say that for some time now the Rationalist position has held sway, there is a condition that is still approached in a manner that would be quite acceptable to the other schools.

\section{References}

1. Aboulker $\mathrm{H}$ : Meningites otitiques gueries [seize observations personelles.] Rev de Laryng 40:193-217, 1919

2. Adson AW: Pseudobrain abscess. Surg Clin North Am 4: 503-512, 1924

3. Aisenberg RM, Rottenberg DA: The pathogenesis of pseudotumor cerebri-a mathematical analysis. J Neurol Sci 48:51-60, 1980

4. Beaumont GE, Hearn JB: A case of reversible papilloedema due to heart failure. BMJ 1:50, 1948

5. Beller AJ: Benign post-traumatic intracranial hypertension. J Neurol Neurosurg Psychiatry 27:149-152, 1964

6. Bercaw BL, Greer M: Transport of intrathecal ${ }^{131}$ I risa in benign intracranial hypertension. Neurology 20:787-790, 1970

7. Bering EA, Salibi NA: Production of hydrocephalus by increased cephalic venous pressure. Arch Neurol Psychiat 81: 693-698, 1959

8. Boddie HG, Banna M, Bradley WG: "Benign" intracranial hypertension. A survey of the clinical and radiological features, and long-term prognosis. Brain 97:313-326, 1974

9. Brooks DJ, Beaney RP, Leenders KL et al: Regional cerebral oxygen utilisation, blood flow, and blood volume in benign intracranial hypertension studied by positron emission tomography. Neurology 35:1030-1034, 1985

10. Brourman ND, Spoor TC, Ramocki JM: Optic nerve sheath decompression for pseudotumor cerebri. Arch Ophthalmol 106: 1378-1383, 1988

11. Buchheit WA, Burton C, Haag B et al: Papilledema and idiopathic intracranial hypertension. N Engl J Med 280:938-942, 1969

12. Bulens C, De Vries WA, Van Crevel H: Benign intracranial hypertension. A retrospective and follow-up study. J Neurol Sci 40:147-157, 1979

13. Cairns H: Abscess of the brain. J Laryngol Otol 45:385-397, 1930

14. Cameron AJ: Marked papilloedema in pulmonary emphysema. Br J Ophthalmol 17:167-169, 1933

15. Carter RB: On the operation of opening the sheath of the optic nerve for relief of pressure. BMJ 399-401, 1889

16. Carter RB: On retrobulbar incision of the optic nerve in cases of swollen disc. Brain 10:199-209, 1887

17. Corbett JJ, Savino PJ, Thompson HS, et al: Visual loss in pseudotumor cerebri. Follow-up of 57 patients from five to 41 years and a profile of 14 patients with permanent severe visual loss. Arch Neurol 39:461-474, 1982 
18. Dandy WE: Intracranial pressure without brain tumor; diagnosis and treatment. Ann Surg 106:492-513,1937

19. Dandy WE, Blackfan KD: Internal hydrocephalus. An experimental, clinical and pathological study. Am J Dis Child 8: 406-482, 1914

20. Davidoff LM: Pseudotumor cerebri. Neurology 6:605-615, 1956

21. Davidoff LM, Dyke CG: Hypertensive meningeal hydrops: syndrome frequently following infection in the middle ear or elsewhere in the body. Am J Ophthalmol 20:908-927, 1937

22. De Wecker L: On incision of the optic nerve in cases of neuroretinitis. Int Ophthalmol Repts 4:11-12, 1872

23. Evans MG: Bilateral jugular vein ligation following bilateral suppurative mastoiditis. Ann Otol Rhinol Laryngol 51: 615-625, 1942

24. Feldman MH, Schlezinger NS: Benign intracranial hypertension associated with hypervitaminosis A. Arch Neurol 22:1-7, 1970

25. Foley J: Benign forms of intracranial hypertension. Toxic and otitic hydrocephalus. Brain 78:1-41, 1955

26. Frazier CH: Cerebral pseudotumors. Arch Neurol Psychiatry 24:1117-1132, 1930

27. Frenckner P: Sinography. A method of radiography in the diagnosis of sinus thrombosis. J Laryngol Otol 52:530-561, 1937

28. Gardner WJ: Otitic sinus thrombosis causing intracranial hypertension. Arch Otolaryngol 30:253-268, 1939

29. Gowers WR: A Manual of Diseases of the Nervous System. London: Churchill, 1892-93

30. Gowers WR: Optic neuritis in chlorosis. BMJ 1:796-797, 1881

31. Greer M: Benign intracranial hypertension. III Pregnancy. Neurology 13:670-672, 1963

32. Greer M: Benign intracranial hypertension. IV Menarche. Neurology 13:569-573,1964

33. Greer M: Benign intracranial hypertension. V Menstrual dysfunction. Neurology 14:668-673, 1964

34. Greer M: Benign intracranial hypertension. VI Obesity. Neurology 15:382-388, 1965

35. Guidetti B, Guiffre R, Gambacorta D: Follow-up study of 100 cases of pseudotumor cerebri. Acta Neurochir 18:259-267, 1968

36. Gutgold-Glen H, Kattah JC, Chavis RM: Reversible visual loss in pseudotumor cerebri. Arch Ophthalmol 102:403-406, 1984

37. Guthrie TC, Dunbar HS, Karpell B: Ventricular size and chronic increased intracranial venous pressure in the dog. J Neurosurg 33:407-414, 1970

38. Hankinson RJ (ed): Galen On Antecedent Causes. Cambridge, UK: Cambridge University Press, 1998, pp 7-47

39. Hitchcock ER, Cowie RA: Sino-jugular venous graft in otitic hydrocephalus. Acta Neurochir 59:187-193, 1981

40. Hughlings J, et al: Discussion on the relation between optic neuritis and intracranial disease. Trans Ophthalmol Soc UK 1: $60-115,1880-1881$

41. Ibrahimi A, Ouammou A, Assamti O, et al: Hypertension intracranienne dite "benign" et maladie de Behcet. Neurochirurgie 30:263-268, 1984

42. Janny P, Chazal J, Colnet G, et al: Benign intracranial hypertension and disorders of CSF absorption. Surg Neurol 15: 168-174, 1981

43. Johnston I: Reduced C.S.F. absorption syndrome. Reappraisal of benign intracranial hypertension and related conditions.Lancet $2: 418-420,1973$

44. Johnston I, Hawke S, Halmagyi M, et al: The pseudotumor syndrome. Disorders of CSF circulation causing intracranial hypertension without ventriculomegaly. Arch Neurol 48:740-747, 1991

45. Johnston I, Morgan MK: A familial coincidence of pseudotumor cerebri and communicating hydrocephalus. Neurosurgery 28:727-729, 1991
46. Johnston I, Paterson A: Benign intracranial hypertension. I Diagnosis and prognosis. Brain 97:289-300, 1974

47. Johnston I, Paterson A: Benign intracranial hypertension. II CSF pressure and circulation. Brain 97:301-312, 1974

48. Karahalios DG, Rekate HL, Khayata MH, et al: Elevated intracranial venous pressure as a universal mechanism in pseudotumor cerebri of varying etiologies. Neurology 46:198-202, 1996

49. Keltner JL: Optic nerve sheath decompression. How does it work? Has its time come? Arch Ophthalmol 106:1365-1369, 1988

50. King JO, Mitchell PJ, Thomson KR, et al: Cerebral venography and manometry in idiopathic intracranial hypertension. Neurology 45:2224-2228, 1995

51. Kollar C, Parker G, Johnston I: Endovascular treatment of cranial venous sinus obstruction resulting in pseudotumor syndrome. Report of three cases. J Neurosurg 94:646-651, 2001

52. Laurence BM, Matthews WB, Shephard RH: Raised intracranial pressure associated with triamcinolone. Lancet 2:701-702, 1960

53. Lawford JB: A case of double optic neuritis following purpura. Trans Ophthalmol Soc UK 2:86-89, 1881-1882

54. Lepore FE: Toward a definition of papilledema: a historical review, 1851-1911. Surg Neurol 17:178-180, 1982

55. Liedler R [abstract by Tweedie AR]: Otitic septic general infection with bilateral optic neuritis. J Laryngol Otol 43:672-673, 1928

56. Lillie HI, Lillie WI: Choked discs in association with surgical mastoid disease without apparent intracranial involvement. Arch Otolaryngol 2:355-361, 1925

57. Martins AN: Resistance to drainage of cerebrospinal fluid: clinical measurement and significance. J Neurol Neurosurg Psychiatry 36:313-318, 1973

58. Mathew NT, Meyer JS, Ott EO: Increased cerebral blood volume in benign intracranial hypertension. Neurology 25: 646-649, 1975

59. McAlpine D: Toxic hydrocephalus. Brain 60:180-203, 1937

60. McCullagh EP: Menstrual edema with intracranial hypertension (pseudotumor cerebri). Cleveland Clin Q 8:202-212, 1941

61. Millen JW, Woollam DHM, Lamming GE: Congenital hydrocephalus due to experimental hypovitaminosis A. Lancet 2: 679-683, 1954

62. Morrice G, Havenar WH, Capetansky F: Vitamin A intoxication as a cause of pseudotumor cerebri. JAMA 173: $1802-1805,1960$

63. Mygind H: Benign forms of otogenic meningitis. J Laryngol Rhinol Otol 37:597-612, 1922

64. Newton Pitt G: An analysis of 57 fatal cases of ear disease and of the complication which led to death. BMJ 1:643-647, 1890

65. Nonne M: Ueber Falle vom Symptomkomplex "Tumor Cerebri" mit Ausgang in Heilung (Pseudotumor Cerebri). Dtsch Z Nervenheil 27:169-216, 1904

66. Passot R: Meningites et etats meninges aseptiques d'origine otique. These de Paris, G Steinheil, 1913

67. Quincke H: Meningitis serosa. Samml Klin Vortr, Leipzig 67: Inn Med 23:655, 1893

68. Quincke H: Ueber Meningitis serosa und verwande Zustande. Dtsch Z Nervenheil 9:140-168, 1897

69. Ray BS, Dunbar HS: Thrombosis of the dural venous sinuses as a cause of pseudotumor cerebri. Ann Surg 134:376-386, 1951

70. Reid AC, Teasdale GM, Matheson MS, et al: Serial ventricular volume measurements: Further insights into the aetiology and pathogenesis of benign intracranial hypertension. J Neurol Neurosurg Psychiatry 44:636-640, 1981

71. Rottenberg DA, Foley KM, Posner JB: Hypothesis: the pathogenesis of pseudtuomor cerebri. Med Hypotheses 6:913-918, 1980

72. Rubin RC, Henderson ES, Ommaya AK, et al: The production 


\section{History of pseudotumors}

of cerebrospinal fluid in man and its modification by acetazolamide. J Neurosurg 25:430-436, 1966

73. Sahs AL, Hyndman OR: Intracranial hypertension of unknown cause. Arch Surg 38:428-442, 1939

74. Sahs AL, Joynt RJ: Brain swelling of unknown cause. Neurology 6:791-803, 1956

75. Sergott RC, Savino PJ, Bosley JM: Modified optic nerve sheath decompression provides long-term visual improvement for pseudotumor cerebri. Arch Ophthalmol 106:1384-1390, 1988

76. Shiozawa Z, Yoshida M, Kobayashi K, et al: Superior sagittal sinus thrombosis and systemic lupus erythematosis. Ann Neurol 20: 272,1986

77. Silbergleit R, Junck L, Gebarski SS, et al: Idiopathic intracranial hypertension (pseudotumor cerebri): MR imaging. Radiology 170:207-209, 1989

78. Smith JL, Hoyt WF, Newton TH: Optic nerve sheath decompression for relief of chronic monocular choked disc. Am J Ophthalmol 68:633-639, 1969

79. Sugerman HJ, DeMaria EJ, Felton WL III, et al: Increased intraabdominal pressure and cardiac filling pressures in obesity-associated pseudotumor cerebri. Neurology 49:507-511, 1997

80. Symonds CP: Hydrocephalus and focal cerebral symptoms in relation to thrombophlebitis of the dural venous sinuses and cerebral veins. Brain 60:531-550, 1937

81. Symonds CP: Otitic hydrocephalus. BMJ 1:53, 1932

82. Symonds CP: Otitic hydrocephalus. Brain 54-55-71, 1931

83. Symonds CP: Otitic hydrocephalus. Neurology 6:681-685, 1956

84. Taylor J and others: Diseases of the optic nerve. Trans Ophthal Soc UK 14:105-119, 1894
85. Thomas WA: Generalised edema occurring only at the menstrual period. JAMA 101:1126-1127, 1933

86. Walker AE, Adamkiewicz JJ: Pseudotumor cerebri associated with prolonged corticosteroid therapy: report of four cases. JAMA 188:779-784, 1964

87. Wall M, George D: Idiopathic intracranial hypertension. A prospective study of 50 patients. Brain 114:155-180, 1991

88. Warrington WB: Intracranial serous effusions of inflammatory origin. Q J Med 7:93-118, 1914

89. Weisberg LA: Benign intracranial hypertension. Medicine 54: 197-207, 1975

90. Weiss MH, Nulsen FE: The effect of glucocorticoids on CSF flow in dogs. J Neurosurg 32:452-458, 1970

91. Williamson RT, Roberts E: Remarks on the diagnosis and prognosis in 100 cases of double optic neuritis with headache. Lancet $1: 1350-1352,1900$

92. Wilson DH, Gardner WJ: Benign intracranial hypertension with particular reference to its occurrence in fat young women. Can Med Assoc J 95:102-105, 1966

93. Zuidema GD, Cohen SJ: Pseudotumor cerebri. J Neurosurg 11:433-441, 1954

Manuscript received June 28, 2001.

Accepted in final form July 12, 2001.

This work was supported by funds from the Madeline Foundation for Neurosurgical Research and the Sydney University Medical Foundation, Wood Grant.

Address reprint requests to: Ian Johnston, M.D., Ph.D., F.R.C.S., GPO Box 811, Hobart, Tasmania 7001, Australia. email: hdtd@ bigpond.com. 